\title{
The basic characteristics and spatial patterns of global cultivated land change since the $1980 \mathrm{~s}$
}

\author{
YAO Ziyan", "ZHANG Lijuan", TANG Shihao², LI Xiaxiang ${ }^{1}$, HAO Tiantian ${ }^{1}$
}

1. Key Laboratory of Remote Sensing Monitoring of Geographic Environment, Harbin Normal University, Harbin 150025, China;

2. Key Laboratory of Radiometric Calibration and Validation for Environmental Satellites, National Satellite Meteorological Center, CMA, Beijing 100081, China

\begin{abstract}
In this paper, we analyzed the spatial patterns of cultivated land change between 1982 and 2011 using global vector-based land use/land cover data. (1) Our analysis showed that the total global cultivated land area increased by $528.768 \times 10^{4} \mathrm{~km}^{2}$ with a rate of $7.920 \times 10^{4}$ $\mathrm{km}^{2} / \mathrm{a}$, although this increasing trend was not significant. The global cultivated land increased fastest in the 1980s. Since the 1980s, the cultivated land area in North America, South America and Oceania increased by $170.854 \times 10^{4} \mathrm{~km}^{2}, 107.890 \times 10^{4} \mathrm{~km}^{2}$, and $186.492 \times 10^{4}$ $\mathrm{km}^{2}$, respectively. In contrast, that in Asia, Europe and Africa decreased by $23.769 \times 10^{4} \mathrm{~km}^{2}$, $4.035 \times 10^{4} \mathrm{~km}^{2}$ and $86.76 \times 10^{4} \mathrm{~km}^{2}$, respectively. Furthermore, the cultivated land area in North America, South America and Oceania exhibited significant increasing trends of $7.236 \times 10^{4}$ $\mathrm{km}^{2} / \mathrm{a}, 2.780 \times 10^{4} \mathrm{~km}^{2} / \mathrm{a}$ and $3.758 \times 10^{4} \mathrm{~km}^{2} / \mathrm{a}$, respectively. On the other hand, that of Asia, Europe and Africa exhibited decreasing trend rates of $-5.641 \times 10^{4} \mathrm{~km}^{2} / \mathrm{a},-0.831 \times 10^{4} \mathrm{~km}^{2} / \mathrm{a}$ and $-0.595 \times 10^{4} \mathrm{~km}^{2} / \mathrm{a}$, respectively. Moreover, the decreasing trend in Asia was significant. (2) Since the 1980s, the increase in global cultivated lands was mainly due to converted grasslands and woodlands, which accounted for $53.536 \%$ and $26.148 \%$ of the total increase, respectively. The increase was found in southern and central Africa, eastern and northern Australia, southeastern South America, central US and Alaska, central Canada, western Russia, northern Finland and northern Mongolia. Among them, Botswana in southern Africa experienced an $80 \%-90 \%$ increase, making it the country with the highest increase worldwide. (3) Since the 1980s, the total area of cultivated lands converted to other types of land was $1071.946 \times 10^{4} \mathrm{~km}^{2}$. The reduction was mainly converted to grasslands and woodlands, which accounted for $57.482 \%$ and $36.000 \%$, respectively. The reduction occurred mainly in southern Sudan in central Africa, southern and central US, southern Russia, and southern European countries including Bulgaria, Romania, Serbia and Hungary. The greatest reduction occurred in southern Africa with a $60 \%$ reduction. (4) The cultivated lands in all the continents analyzed exhibited a trend of expansion to high latitudes. Additionally, most countries displayed an expansion of newly increased cultivated lands and the reduction of the original cultivated lands.
\end{abstract}

Keywords: cultivated lands; characteristics of change; spatial pattern; global; $1980 \mathrm{~s}$

Received: 2016-12-28 Accepted: 2017-01-20

Foundation: National Natural Science Foundation of China, No.42171217

Author: Yao Ziyan, Master, specialized in studies of changes in land use and land cover. E-mail: 282976152@qq.com

"Corresponding author: Zhang Lijuan, Professor, E-mail: zlj19650205@163.com 


\section{Introduction}

The change of ecosystem and land cover due to human activities is one of the most important factors affecting the natural ecosystem of the Earth (Ramankutty et al., 2006; Tian et al., 2012; Tao et al., 2013; He et al., 2016). Since the 20th century, the land cover change caused by human activities has gradually become a "global" phenomenon associated with the Earth system (Chhabra et al., 2006; Liu et al., 2014). Land use and cover change (LUCC) not only affects regional sustainable development, but also impacts global change to the same extent as natural elements. LUCC has become the main contributor to the change in ecosystem in some regions (Shi et al., 2006; Findell et al., 2009; Forster et al., 2007). Agriculture, one of the most important human activities affecting land use, so far has involved 1/3 of the Earth's terrestrial surface, which has replaced most of the vegetation on the same surface (Ramankutty et al., 2005; Godfray et al., 2010; Goldewijk et al., 2011). Although humans have used land resources to satisfy their survival needs through farming activities, this type of land change affects the Earth's surface-atmosphere system (Ramankutty et al., 2006). In response, the feedback between agriculture and climate will change the capabilities of the ecosystem to meet human needs (Ye et al., 2009). Therefore, cultivated land change has become the most important content of LUCC research.

Both domestic and foreign scientists have conducted many studies on cultivated land change at different spatial and temporal scales. Although ample data exists, not much research has been conducted examining cultivated land on a global scale. Ramankutty and Foley combined satellite data with national and subnational agricultural inventory data and created the global $10 \mathrm{~km} \mathrm{spa-}$ tial resolution dataset of the early 1990s. They determined that the global cultivated land area in the early 1990s was 18 million $\mathrm{km}^{2}$ and then analyzed the spatial change of the global cultivated lands (Ramankutty and Foley et al., 1998). In 1999, Ramankutty and Foley reconstructed a historical cropland dataset from 1700 to 1992 using the "hindcast" modeling technique. They reported that the global cultivated land area had increased throughout the past three centuries. Moreover, after 1700, Europe had the most rapid cultivated land expansion, followed by North America and the former Soviet Union; the largest increase in cultivated lands was at the cost of sacrificing woodlands and grasslands (Ramankutty and Foley, 1999). Based on global agricultural inventory data and satellite data, Ramankutty et al. reconstructed the global cropland vector map for the year 2000 and concluded that the global cultivated land area was approximately 15 million $\mathrm{km}^{2}$. The larger proportion of croplands was found in South and Southeast Asia, Europe, and the eastern part of the Mississippi River basin in the United States, while a smaller proportion of croplands was found in Canada and the northern part of South America (Ramankutty et al., 2008). According to the History Database of the Global Environment (HYDE), Goldewijk et al. (2011) determined that the global cultivated land area had increased by 5.5 -fold in the past three centuries, with the increase in cultivated lands mainly due to converted woodlands and grasslands. Through the calibration and analysis of cultivated land data from multiple sources, in 2005 Lepers et al. found that the cultivated lands increased in all of the continents analyzed between 1981 and 1990. The increased area was mainly located in the southeastern part of Asia, Bangladesh, the Indus River Basin, the Middle East, Central Asia and the Great Plains of the United States, and the decrease in cultivated lands occurred more in the southeastern United States and eastern China (Lepers et al., 2005). Additionally, based on the statistical databases from the World Food and Agriculture Organization (FAO) of the United Nations and the World Bank Zhao (2012) analyzed the dynamic changes of cultivated lands in the 17 countries whose population was expected to exceed 100 million by 2050 and the top 10 countries with the largest 
cultivated land area. The results showed that most of the countries studied showed a decreasing trend of cultivated lands, and more than $90 \%$ of the countries exhibited a reduction in cultivated land area per capita (Zhao, 2012). In summary, although these studies on the spatiotemporal change of cultivated land were conducted on a global scale, most of them focused on the changes occurring before the 1990s. However, with global warming and the continuous update of global cultivated land data, people are paying more attention to the recent spatiotemporal change of global cultivated land.

In this study, we analyzed the change of global cultivated land area and the characteristics of spatial pattern change since the 1980s using the global land cover dataset CG-LTDR which has been jointly developed by the Institute of Geographic Sciences and Natural Resources Research, Chinese Academy of Sciences and the National Satellite Meteorological Center. Our data could provide the basis for investigating the effect of human activities on the Earth's lands, ensuring the sustainable development and use of cultivated land resources and guaranteeing world crop safety.

\section{Data sources and processing}

\subsection{Global data of cultivated land and validation}

With the rapid development of satellite data and remote sensing technologies, there are a few sets of global land cover data products available internationally. In recent years, China has released several sets of global land cover data products with high resolution, such as FROM-GLC and GlobeLand30. Nevertheless, the global cultivated land usage data in each year after the 1980s are still very limited. In this study, we used the global land cover data product CG-LTDR. CG-LTDR has the following features: (1) Achieves quantitative assimilation on the pixel level by assimilating the MODIS data with a resolution of $500 \mathrm{~m}$ into AVEHRR data of $0.05^{\circ}$ resolution and creates a long time series of land cover category data of the same spatial resolution in the time scale of 1982 to 2011. (2) Uses a new algorithm for land cover classification, which is known as hierarchy classification. It divides the region into major categories based on their geographic features, and then is further divided into subcategories based on subtle geographic features. It is characterized by simplifying the classification features and filtering the noise information, greatly reducing the number of classification features, and converting implicit information into explicit information. (3) CG-LTDR divides the underlying surface into 15 types of land use, including water (lake), ice and snow, wasteland, sparse vegetation, city, wetland, evergreen coniferous forest, deciduous coniferous forest, evergreen broadleaf forest, deciduous broadleaf forest, shrub, cultivated land, grassland, mixed grassland and woodland, and moss and lichens.

The spatial distribution maps of global land use in 1982, 1990, 2000 and 2011 are shown in Figure 1.

This data product has been used as basic data in multiple studies and is validated. Shi et al. (2015) validated the classification accuracy of CG-LTDR in China. Its overall classification accuracy was as high as $65.57 \%$, which was similar or even higher compared with other global land use data (IGBP DISCOVER, UMD, GLC2000 and MODIS LAND COVER). Based on the above study, Shang et al. (2015) and Liu et al. (2015) generated the global surface albedo product and leaf area index data, which have been used in the resource library of global and regional climate models multiple times.

To further validate the data accuracy of CG-LTDR in the regions outside of China, we compared the CG-LTDR data product with three other global land use data products including 


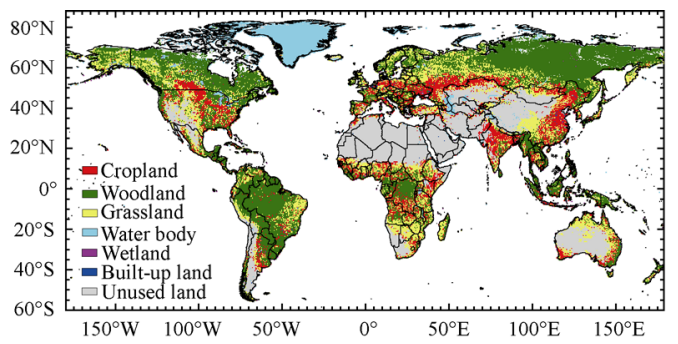

(a) 1982

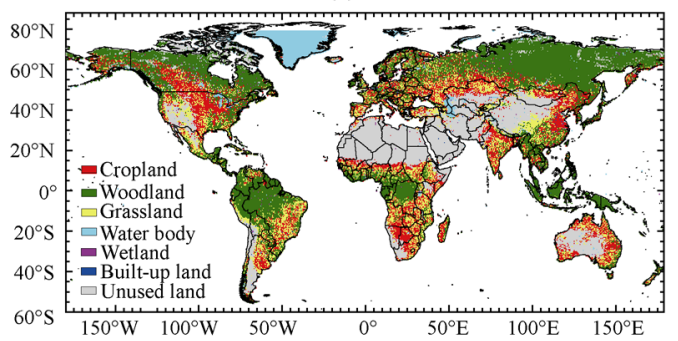

(c) 2000

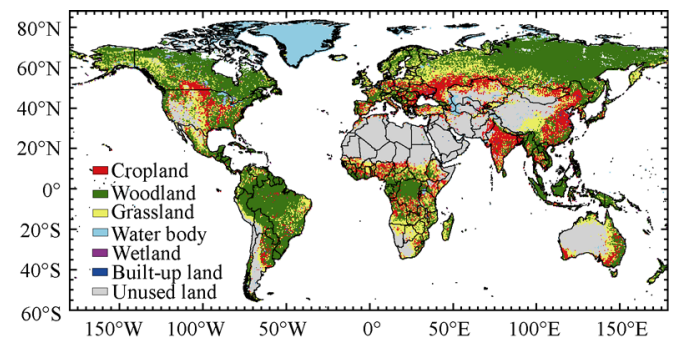

(b) 1990

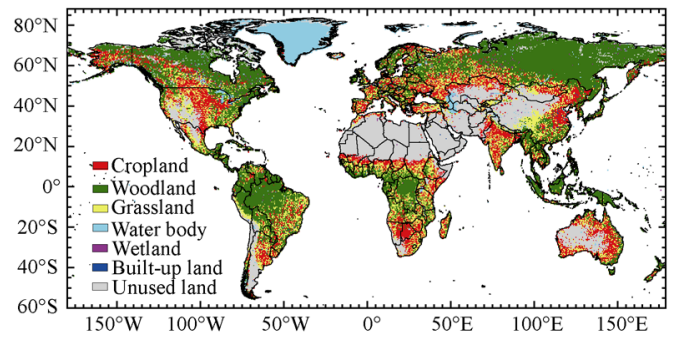

(d) 2011

Figure 1 The spatial distribution maps of global land use in 1982, 1990, 2000 and 2011

ESA-GlobCover from the European Space Agency, food and agriculture database from FAO and NASA-MCD12Q1 from the National Aeronautics and Space Administration (NASA). We downloaded three sets of data after 2010 from http://www.esa-landcover-cci.org, http://www.fao.org, and https://ladsweb.nascom.nasa.gov/data/search.html. We employed the Kappa coefficient to evaluate the spatial agreement between CG-LTDR and the other three sets of data. Due to the slight difference in land use classification from different data products, we combined some types of land use in the current study and focused on the degree of agreement for the spatial distribution of the major types of land use among different data products. The Kappa coefficient is a parameter used to compare the degree of spatial agreement between two images (Hudson, 1987). A Kappa coefficient with a value of $0-0.20$ indicates the agreement as none to slight, $0.21-0.40$ as fair, $0.41-0.60$ as moderate, $0.61-0.80$ as substantial, and $0.81-1$ as almost perfect. Our results showed that CG-LTDR had substantial agreement with ESA-GlobCover data and the FAO database and had almost perfect agreement with the NASA-MCD12Q1 data (Table 1).

Table 1 The Kappa values for global land use data between different data products

\begin{tabular}{cccc}
\hline Global land use dataset & ESA-GlobCover & FAO food and agriculture database & NASA-MCD12Q1 \\
\hline Kappa value & 0.6147 & 0.7104 & 0.8184 \\
Agreement & Substantial & Substantial & Almost perfect \\
\hline
\end{tabular}

\subsection{Average annual global temperature data}

Average annual global temperature data come from the meteorological elements database of the Climatic Research Unit (CRU) of the University of East Anglia in the United Kingdom. It is a comprehensive, high-resolution and continuous surface meteorological elements database, which includes data for temperature, precipitation, wind speed, evaporation and dates of frost. The data begins in 1901 and has a time resolution of one month. It covers all the lands in the world, and all the deserts and plateaus have been measured. In this paper, we chose the high-resolution gridded dataset of surface climatic variables CRU-TS3.22, and downloaded the monthly average data of 
global temperature between 1982 and 2011 from http://www.cru.uea.ac.uk/data. In order to analyze the spatial distributions and changes of global land temperature, we used the "To Raster" tool in the module of Spatial Analyst Tools in ArcGIS software to convert the original data into raster data. The reference coordinate system we adopted was WGS84.

\section{Methods of analyses}

\subsection{Tendency rate}

We conducted a trend analysis of the time series data of certain meteorological elements by linear trend estimation. For a series of data $y(x)(x=1,2, \ldots, n)$, the original series was fitted by a linear function (Ma et al., 1993):

$$
Y=a x+b
$$

The positive or negative value of $a$ represents the direction of the data series over time. Its absolute value represents the rate of change, and $b$ is the intercept.

\subsection{Land use dynamic degree model}

Land use change rate can be measured by using a land use dynamic model. It can not only characterize the time series change of a single type of land use, but can also analyze the overall status of the regional land use dynamics and the intra-regional difference (Liu, 2000). The formula is as follows.

$$
K=\frac{U_{a}-U_{b}}{U_{a}} \times \frac{1}{T} \times 100 \%
$$

where $K$ is the dynamic degree of the type of land use during the study period. $U_{a}$ and $U_{b}$ are the quantities of the type of land use in the first year and last year of the study period, respectively. $T$ is the length of study time. When $T$ is set as years, $K$ is the annual change rate for the type of land use in the study area. In the calculations of this paper, the unit was $0.05^{\circ} \times 0.05^{\circ} . U_{a}$ and $U_{b}$ corresponded to year 1982 and year 2011, respectively.

\section{Results and analyses}

\subsection{The spatiotemporal pattern change of global cultivated lands since the 1980s}

Since the 1980s, the global cultivated land area exhibited an increasing trend at a rate of $7.920 \times 10^{4} \mathrm{~km}^{2} / \mathrm{a}$, although this increase was not statistically significant $(p>0.05)$. In 1982 , the area was $1939.573 \times 10^{4} \mathrm{~km}^{2}$, which increased by $528.768 \times 10^{4} \mathrm{~km}^{2}$ to $2468.340 \times 10^{4} \mathrm{~km}^{2}$ in 2011 . The global cultivated land area exhibited the change characteristics of increase-decrease-increase over the three decades. In particular, the area increased in the 1980s and the 2000s, but decreased in the 1990s. In addition, the increasing rate in the 1980s was 3.7-fold higher than that of the 2000s. From here, we can see that the global cultivated land area increased most rapidly in the 1980s (Figure 2 and Table 2).

Since the $1980 \mathrm{~s}$, the area of other types of land use converted into cultivated lands was $1599.753 \times 10^{4} \mathrm{~km}^{2}$ globally, while $1071.946 \times 10^{4} \mathrm{~km}^{2}$ of cultivated land were converted to other types of land use globally (Table 3 ). The area converted into cultivated lands was larger than that converted from cultivated lands. The global increase in cultivated lands was mainly due to con- 
verted grasslands, woodlands and unused lands, accounting for $53.536 \%, 26.148 \%$ and $18.403 \%$ of the total increase, respectively. That is to say that half of the global increased cultivated lands were converted from grasslands. On the other hand, since the 1980s, the global decrease in cultivated lands was principally due to converted grasslands, woodlands and unused lands, which accounted for a decrease of $57.482 \%, 36.000 \%$ and $4.072 \%$, respectively. The global decrease in cultivated lands was mainly due to conversion into grasslands and woodlands.
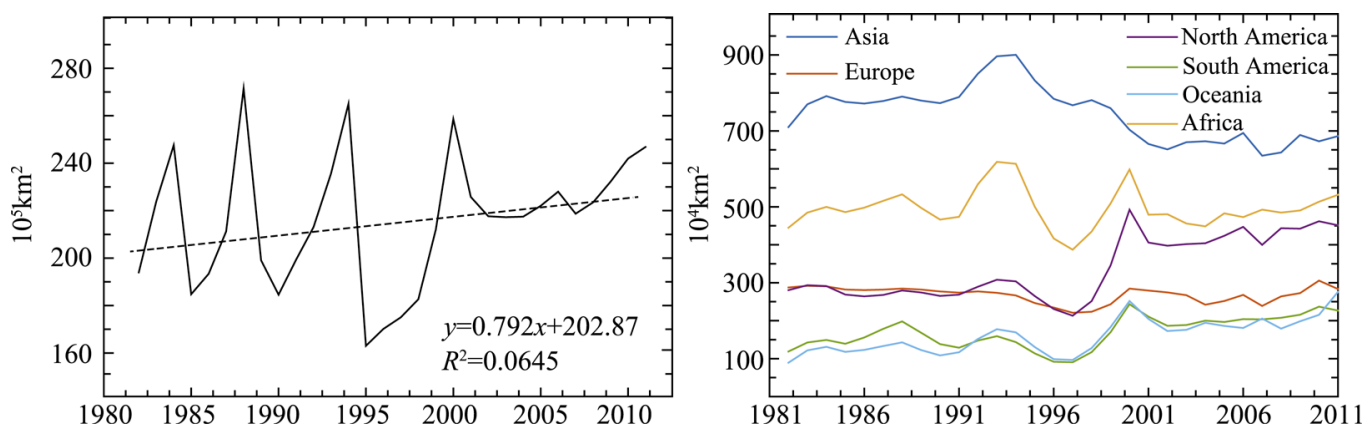

Figure 2 The interannual change curve of cultivated land area in different continents since the 1980s

Table 2 The characteristics of cultivated land change in different continents since the 1980s

\begin{tabular}{|c|c|c|c|c|c|c|c|c|}
\hline & Year & Asia & Europe & Africa & North America & South America & Oceania & Global \\
\hline \multirow{4}{*}{$\begin{array}{l}\text { Cultivated } \\
\text { land area } \\
\left(10^{4} \mathrm{~km}^{2}\right)\end{array}$} & 1982 & 710.016 & 287.521 & 444.869 & 280.407 & 118.850 & 89.331 & 1939.573 \\
\hline & 2011 & 686.247 & 283.486 & 531.629 & 451.261 & 226.740 & 275.823 & 2468.340 \\
\hline & $\begin{array}{c}\text { Average annual } \\
\text { cultivated } \\
\text { land area }\end{array}$ & 749.801 & 267.166 & 494.680 & 333.512 & 167.752 & 158.975 & 2171.886 \\
\hline & $\begin{array}{l}\text { Cultivate land } \\
\text { area change } \\
(1982-2011)\end{array}$ & -23.769 & -4.035 & 86.760 & 170.854 & 107.89 & 186.492 & 528.767 \\
\hline \multirow[t]{4}{*}{ Tendency rate } & $1982-2011$ & $-5.641^{*}$ & -0.813 & -0.595 & $7.236^{* *}$ & $2.780^{*}$ & $3.758^{*}$ & 6.852 \\
\hline & 1982-1989 & 2.382 & -1.136 & 9.812 & -2.277 & 10.080 & 2.226 & 20.650 \\
\hline & 1990-1999 & -1.335 & $-8.769 *$ & -9.050 & -6.821 & -3.073 & -0.209 & -29.780 \\
\hline & 2000-2011 & -0.266 & 0.702 & -0.320 & 2.057 & 1.297 & 2.039 & 5.553 \\
\hline
\end{tabular}

Table 3 The conversion of global cultivated lands and other types of land use $\left(10^{4} \mathrm{~km}^{2}\right)$

\begin{tabular}{lccccccc}
\hline & Asia & Europe & Africa & North America & South America & Oceania & Global \\
\hline $\begin{array}{l}\text { Land area converted } \\
\text { into cultivated lands }\end{array}$ & 325.826 & 135.203 & 407.844 & 299.867 & 189.500 & 230.331 & 1599.753 \\
$\begin{array}{l}\text { Land area converted } \\
\text { from cultivated lands }\end{array}$ & 349.725 & 139.325 & 321.317 & 129.452 & 81.599 & 43.089 & 1071.946 \\
\hline
\end{tabular}

Since the 1980s, the global increase in cultivated lands was mainly distributed in southern and central Africa, with a concentration in Botswana, Sudan and Mali, mid-eastern and northern Australia, southeastern South America, with a concentration in eastern Brazil and northern Argentina, Central America and Alaska, central Canada, western Russia, northern Finland, and northern Mongolia. The highest percentage increase in cultivated land worldwide occurred in Botswana in southern Africa where there was an $80 \%-90 \%$ increase. Eastern Australia and Alaska in the United States also had a significant increase of $50 \%-60 \%$ in cultivated lands while 
part of southeastern South America increased by $40 \%-50 \%$. On the other hand, the areas with a decrease in cultivated lands became concentrated. The decrease occurred mainly in central Africa with a concentration in southern Sudan, South and Southeast Asia, mid-southern United States, southern Russia, and Bulgaria, Romania, Serbia and Hungary in southern Europe. In addition, the largest decrease in cultivated lands occurred in southern Africa, southeastern United States and southwestern Russia with a 30\%-50\% reduction, while some regions had a reduction of more than $60 \%$ (Figure 3).

The conversion of global cultivated lands had a distinct spatial feature, showing a relatively concentrated regional characteristic. The conversion of grasslands to cultivated lands mostly occurred in the Southern Hemisphere and mid-latitude regions of the Northern Hemisphere. The high latitude regions of the Northern Hemisphere and the eastern part of South America had more woodlands converted to cultivated lands. On the contrary, the conversion of cultivated lands to grasslands occurred in low latitude areas. India, China, Russia and central North America all had concentrated regions of grasslands converted from cultivated lands (Figure 4).

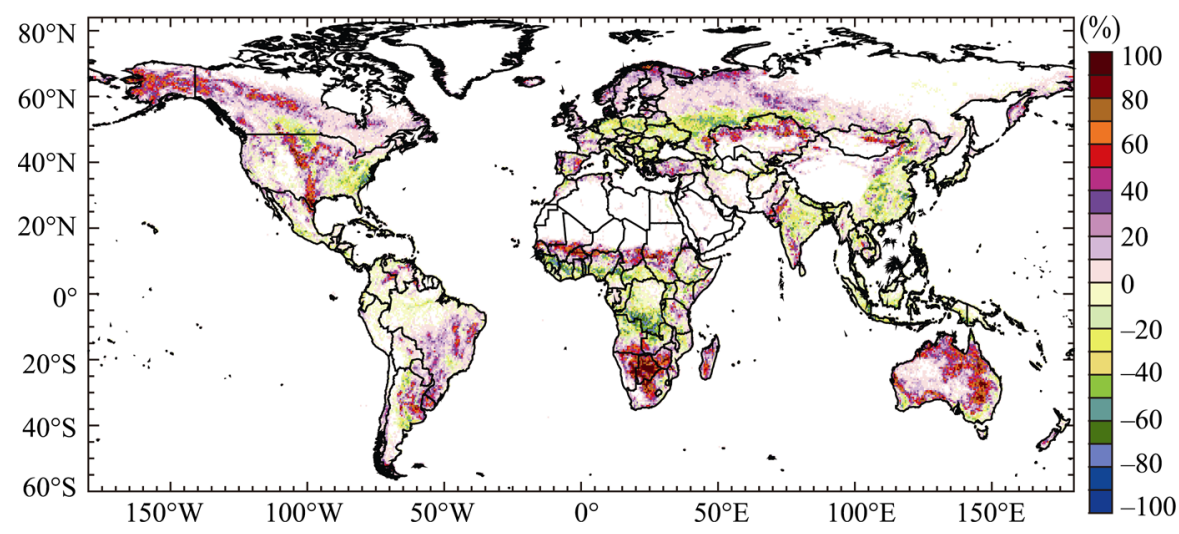

Figure 3 The spatial change of global cultivated lands and the rate of change since the 1980s

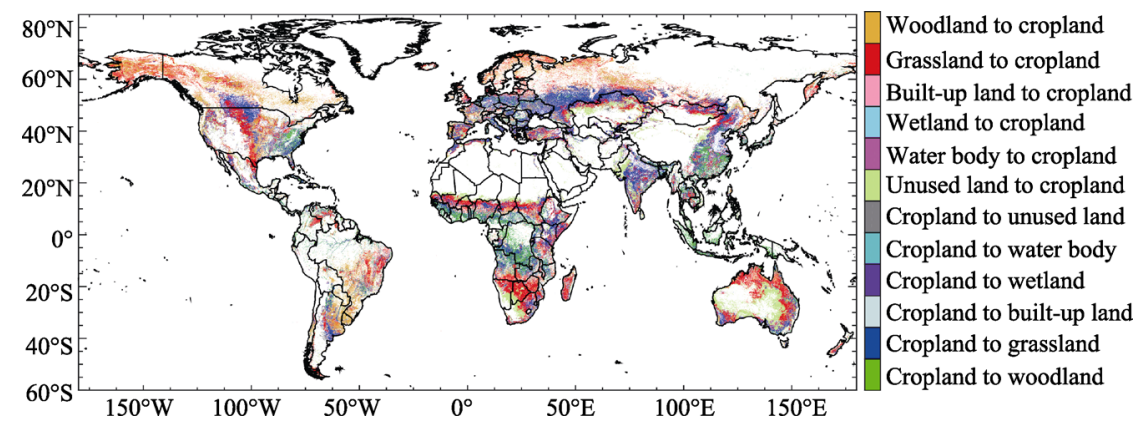

Figure 4 The spatial distribution of global cultivated land conversion since the 1980s

\subsection{The spatial pattern change of cultivated lands in different continents analyzed since the 1980s}

Since the 1980s, the cultivated land areas in North America, South America and Oceania showed increasing trends, while the cultivated land areas in Asia, Europe and Africa showed decreasing trends. Compared to the data from 1982, in 2011 the cultivated land areas in North America, South America and Oceania increased by $170.854 \times 10^{4} \mathrm{~km}^{2}, 107.890 \times 10^{4} \mathrm{~km}^{2}$, and $186.492 \times 10^{4}$ 
$\mathrm{km}^{2}$, respectively. In contrast, in 2011 the cultivated land areas in Asia, Europe and Africa had a respective decrease of $23.769 \times 10^{4} \mathrm{~km}^{2}, 4.035 \times 10^{4} \mathrm{~km}^{2}$ and $86.76 \times 10^{4} \mathrm{~km}^{2}$ (Table 3). Among them, the cultivated land areas in North America and South America showed a significant increasing trend with North America experiencing the fastest rate of increase of $7.236 \times 10^{4} \mathrm{~km}^{2} / \mathrm{a}$. On the other hand, the cultivated land areas of Asia experienced a significant decrease at a rate of $5.641 \times 10^{4} \mathrm{~km}^{2} / \mathrm{a}$. The change of cultivated land area in each continent exhibited different characteristics over the years. South America and Oceania showed the same characteristics as the rest of the world. In Asia and Africa, cultivated land area increased in the 1980s and decreased thereafter. In Europe and North America, the area decreased in the 1980s and 1990s, but increased in the 2000s (Figure 2 and Table 2). The increase in cultivated lands in each continent was mainly converted from grasslands, woodlands and unused lands. In Asia, North America, Africa, South America and Oceania, the highest conversion percentages were from grasslands into cultivated lands, while the highest percentage was due to the conversion of woodlands into cultivated lands in Europe. The second largest percentage was the conversion of the unused lands into cultivated lands in Asia, Africa and Oceania, while the conversion of woodlands into cultivated lands occurred in Europe, North America and South America (Table 4). Regarding the conversion of cultivated lands into other lands, grasslands were the leading type in each continent, followed by woodlands. The sum of these two types accounted for more than $90 \%$ of the total conversion. The percentage of conversion from cultivated lands into grasslands was above $50 \%$ in each continent, with Europe reaching a conversion rate of more than $70 \%$ (Table 5).

Since the 1980s, the newly increased cultivated lands in Asia had been mainly distributed in southern and northwestern India, northern Kazakhstan, northern Mongolia, southwestern Russia, northeastern China, and mid-western Turkey. Among them, in Asia, northern Kazakhstan, northern Mongolia and northwestern India had the greatest percentages of cultivated land increase, being 50\%-60\%. In southern India and mid-western Turkey, the percentages were $40 \%-50 \%$. In contrast, Japan, North Korea, Malaysia and Indonesia had notable decreases in cultivated lands,

Table 4 The area matrix of cultivated lands converted from other types of land use in different continents analyzed and the world since the $1980 \mathrm{~s}\left(\mathrm{~km}^{2}\right)$

\begin{tabular}{|c|c|c|c|c|c|c|c|}
\hline & \multicolumn{7}{|c|}{ Area of cultivated lands converted from other types of land use $\left(\mathrm{km}^{2}\right)$} \\
\hline & Asia & Europe & Africa & North America & South America & Oceania & Global \\
\hline Woodland & 587044.033 & 538977.272 & 497117.371 & 1295193.574 & 1049514.128 & 210610.092 & 4183030.965 \\
\hline Grassland & 1685071.620 & 700578.490 & 2693786.908 & 1527020.934 & 768167.250 & 1168947.585 & 8564519.048 \\
\hline $\begin{array}{l}\text { Construction } \\
\text { land }\end{array}$ & 8745.380 & 3418.037 & 852.623 & 2675.515 & 1455.492 & 125.654 & 17290.898 \\
\hline Wetland & 53106.836 & 29938.381 & 24623.822 & 27727.065 & 16697.013 & 18878.816 & 231618.103 \\
\hline Water area & 12878.212 & 4244.370 & 4824.171 & 7055.778 & 3649.667 & 3989.419 & 57099.131 \\
\hline \multirow[t]{2}{*}{ Unused land } & 911410.987 & 74871.195 & 857230.925 & 138995.122 & 55494.096 & 900758.834 & 2943976.114 \\
\hline & \multicolumn{7}{|c|}{ Area percentages of cultivated lands converted from other types of land use (\%) } \\
\hline Woodland & 18.017 & 39.864 & 12.189 & 43.192 & 55.384 & 9.144 & 26.148 \\
\hline Grassland & 51.717 & 51.817 & 66.050 & 50.923 & 40.537 & 50.751 & 53.536 \\
\hline $\begin{array}{l}\text { Construction } \\
\text { land }\end{array}$ & 0.268 & 0.253 & 0.021 & 0.089 & 0.077 & 0.005 & 0.108 \\
\hline Wetland & 1.630 & 2.214 & 0.604 & 0.925 & 0.881 & 0.820 & 1.448 \\
\hline Water area & 0.395 & 0.314 & 0.118 & 0.235 & 0.193 & 0.173 & 0.357 \\
\hline Unused land & 27.972 & 5.538 & 21.019 & 4.635 & 2.928 & 39.107 & 18.403 \\
\hline
\end{tabular}


Table 5 The area matrix of cultivated lands converted into other types of land use in different continents analyzed and globally since the $1980 \mathrm{~s}\left(\mathrm{~km}^{2}\right)$

\begin{tabular}{|c|c|c|c|c|c|c|c|}
\hline & \multicolumn{7}{|c|}{ Area of cultivated lands converted into other types of land use $\left(\mathrm{km}^{2}\right)$} \\
\hline & Asia & Europe & Africa & North America & South America & Oceania & Global \\
\hline Woodland & 1217276.742 & 300777.368 & 1410706.162 & 399259.025 & 341994.955 & 141504.896 & 3859019.347 \\
\hline Grassland & 2017539.664 & 1065004.971 & 1647566.868 & 788780.992 & 373549.898 & 258183.988 & 6161722.976 \\
\hline $\begin{array}{l}\text { Construction } \\
\text { land }\end{array}$ & 15804.035 & 10816.968 & 1370.660 & 4030.622 & 723.119 & 151.457 & 33117.082 \\
\hline Wetland & 57448.359 & 6470.664 & 17104.849 & 25935.501 & 41131.877 & 6184.790 & 166437.848 \\
\hline Water area & 19388.005 & 2573.700 & 7587.074 & 8548.657 & 15530.140 & 6160.882 & 62663.411 \\
\hline \multirow[t]{2}{*}{ Unused land } & 169794.097 & 7604.133 & 128833.594 & 67964.712 & 43064.184 & 18703.268 & 436504.043 \\
\hline & \multicolumn{7}{|c|}{ Area percentages of cultivated lands converted into other types of land use (\%) } \\
\hline Woodland & 34.807 & 21.588 & 43.904 & 30.842 & 41.911 & 32.840 & 36.000 \\
\hline Grassland & 57.689 & 76.440 & 51.275 & 60.932 & 45.779 & 59.919 & 57.482 \\
\hline $\begin{array}{l}\text { Construction } \\
\text { land }\end{array}$ & 0.452 & 0.776 & 0.043 & 0.311 & 0.089 & 0.035 & 0.309 \\
\hline Wetland & 1.643 & 0.464 & 0.532 & 2.003 & 5.041 & 1.435 & 1.553 \\
\hline Water area & 0.554 & 0.185 & 0.236 & 0.660 & 1.903 & 1.430 & 0.585 \\
\hline Unused land & 4.855 & 0.546 & 4.010 & 5.250 & 5.278 & 4.341 & 4.072 \\
\hline
\end{tabular}

with a $40 \%-50 \%$ decrease observed in some regions. In addition, central India, southeastern China and the southwestern border of Russia all had reductions in cultivated lands. On the other hand, the increase in cultivated lands was mostly due to the conversion of woodlands in Russia and grasslands in Kazakhstan, Mongolia, India and Turkey. The northern boundary of cultivated lands in Asia moved from a latitude of $66^{\circ} \mathrm{N}$ in 1982 to $68^{\circ} \mathrm{N}$ in 2011 (Figures 3 and 5a).

In Europe, the cultivated lands increased in northern Europe and decreased in southern Europe since the 1980s. Several countries in northern Europe, including Norway, Sweden, Finland, Iceland and the United Kingdom had obvious increases of cultivated lands. In particular, northern Finland had the largest increase of $50 \%-60 \%$. Some countries in southern Europe, including Germany, Italy, Ukraine and Romania had notable decreases in cultivated lands of $20 \%-30 \%$ in most regions. In Russia, France, Spain and Portugal, there were both increases and decreases in cultivated lands occurring at the same time. Among these countries, cultivated lands had expanded to mid-northern Russia, while the original cultivated lands were converted into other types of lands in southern Russia. In France, the expansion of cultivated lands was observed in mid-southern areas, and the decrease in northern areas. In Spain, cultivated lands had been expanded to eastern areas and decreased in southwestern areas. In Portugal, the expansion of cultivated lands was seen in mid-northern areas, and the reduction in southern areas. The northern boundary of cultivated lands in Europe moved from a latitude of $55^{\circ} \mathrm{N}$ in 1982 to $71^{\circ} \mathrm{N}$ in 2011 (Figures 3 and 5b).

In Africa, the increase in cultivated lands was mainly distributed in the area of $10^{\circ}-15^{\circ} \mathrm{N}$ and the southern area of $15^{\circ} \mathrm{S}$, and the decrease in cultivated land was mainly located in the area between $10^{\circ} \mathrm{N}$ and $15^{\circ} \mathrm{S}$ since the $1980 \mathrm{~s}$. Overall, the cultivated lands in Africa moved to higher latitude and also decreased to a great extent. Additionally, the southern African Botswana showed the largest percentage increase in cultivated land with a $90 \%-100 \%$ increase. Southeastern Angola, northeastern Namibia, mid-northern South Africa, Zimbabwe, Burkina Faso, southern Chad and southern Sudan also showed a relatively high percentage increase of $50 \%-70 \%$. The per- 
centage increase in cultivated lands in Madagascar was 40\%-60\%. On the other hand, southern areas of the Democratic Republic of the Congo and northeastern Angola showed the highest percentage decrease in cultivated lands, which was $60 \%-70 \%$. With respect to land conversion, the increase in cultivated lands in Africa was primarily due to a conversion into grasslands, while the decrease in cultivated lands was mainly due to conversion of grasslands and woodlands. The northern boundary of African cultivated lands, located south of the Sahara, moved from a latitude of $16^{\circ} \mathrm{N}$ to $17^{\circ} \mathrm{N}$ (Figures 3 and $5 \mathrm{c}$ ).

In North America, the central United States and Alaska, and central Canada showed the highest percentage increase in cultivated land of 50\%-70\%. In the United States, Canada and Mexico, both an increase and decrease in cultivated lands took place. In the United States, the increase in cultivated lands was primarily located in central areas, western areas and Alaska; the increase in Alaska was remarkable. In Canada, the cultivated lands expanded towards the north, while there was a reduction in cultivated lands in the mid-southern areas. The increased cultivated land in Mexico is mainly located in the northeast, while the cultivated land along the west border shows a declining trend. The northern boundary of cultivated land in North America moved from $67^{\circ} \mathrm{N}$ in 1982 to $70^{\circ} \mathrm{N}$ in 2011 (Figures 3 and $5 \mathrm{~d}$ ).

In South America, Uruguay, southeastern Brazil, northeastern Argentina, and northern Columbia, cultivated lands increased by $50 \%-60 \%$ in some areas. In contrast, the cultivated lands in central and northern Argentina reduced significantly by $40 \%-60 \%$. The decrease in cultivated lands in western Brazil and Venezuela was approximately $20 \%$. The cultivated land area in western and eastern Columbia also declined. The cultivated lands showed an expansion in the east and a reduction in the west in many South American countries. The northern boundary of cultivated land in South America moved from 53 ${ }^{\circ} \mathrm{S}$ in 1982 to $55^{\circ} \mathrm{S}$ in 2011 (Figures 3 and 5e).

In Oceania, Australia showed the greatest increase in cultivated lands of $189.165 \times 10^{4} \mathrm{~km}^{2}$. The increased cultivated lands extended from the north, east and south to the inland and were more pronounced in northern and eastern areas with a percentage of $60 \%-70 \%$. In addition, there was a relatively great increase in cultivated lands in the South Island of New
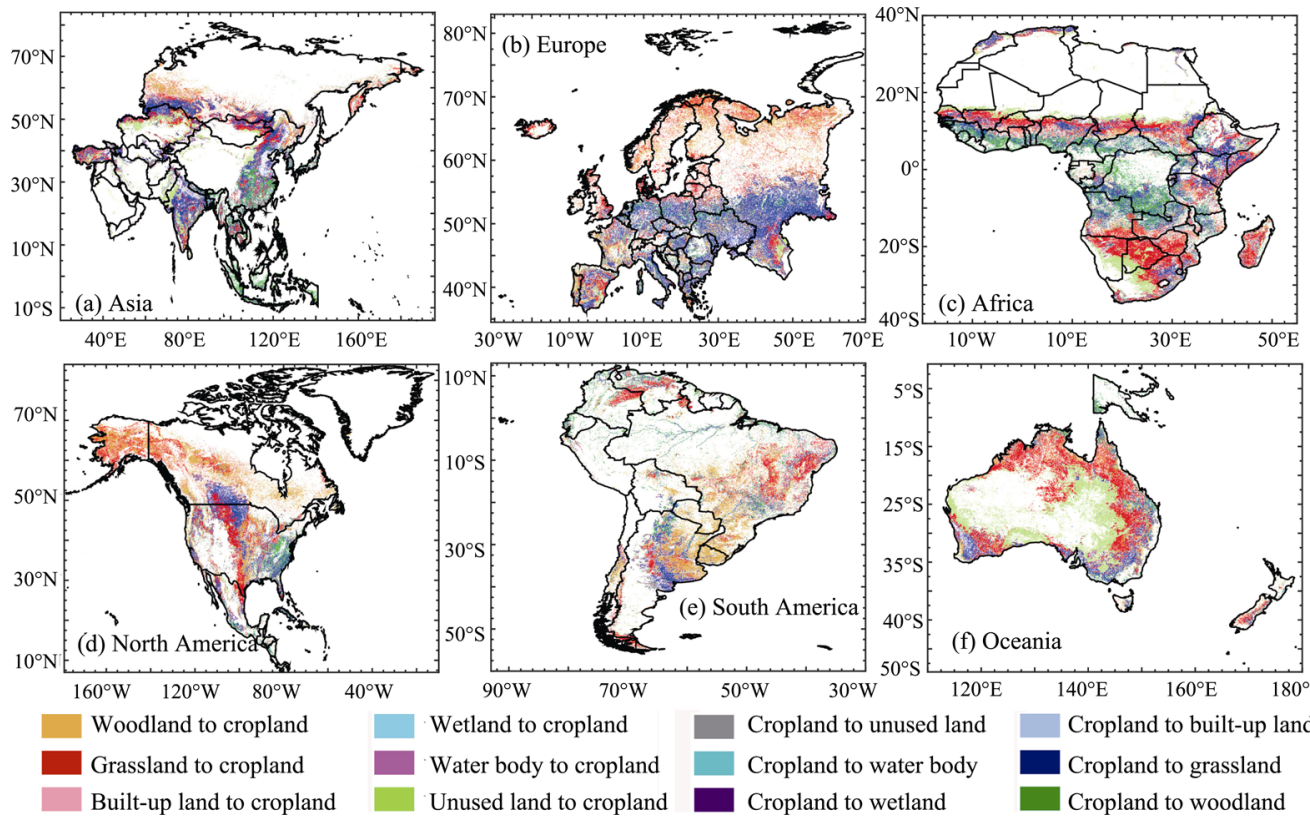

(f) Oceania

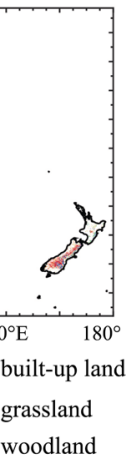

Figure 5 The spatial distribution of cultivated land conversions in different continents since the 1980s 
Zealand which increased by $2904.572 \mathrm{~km}^{2}$, most of which were converted from grasslands. The northern boundary of cultivated land in Oceania moved from $46^{\circ} \mathrm{S}$ in 1982 to $47^{\circ} \mathrm{S}$ in 2011 (Figures 3 and 5f).

\section{Discussion}

In this paper, we used the CG-LTDR global cultivated lands data and analyzed the spatiotemporal characteristics of global cultivated land change since the 1980s. Compared to existing studies, we focused on the time series characteristics and spatial patterns of land area change and revealed the spatial patterns of global cultivated land changes in the past 30 years.

(1) We verified our results by comparing our findings with those from other relevant studies. According to the study periods used in existing studies, we calculated the results of the same periods using CG-LTDR data. The comparison results are shown in Table 6. It can be seen that although we used source data and research methods that are different from other researchers, our results were consistent with the conclusions made by others. This verified the credibility of our research conclusions. In addition, because we combined the spatial vector data, our results were more quantitative than other studies conducted to date. For example, Xie and Cheng (1999) reported that the global cultivated lands showed an increasing trend before 1985 and a decreasing trend between 1985 and 1995. Our data are consistent with these data as we also found that the global cultivated lands had a decreasing trend between 1985 and 1995. Also, we further pointed out that the reduction was not significant at a rate of $19.772 \times 10^{4} \mathrm{~km}^{2} / \mathrm{a}$. Abbas et al. (2009) found that from 1975 to 2005, the cultivated lands in Nigeria expanded towards the southern forest areas, while the original cultivated lands were reduced. With similar findings as Abbas, we further calculated that the expanded area was $214,197.544 \mathrm{~km}^{2}$ towards the southern forest areas, while the original cultivated lands reduced by $187,354.798 \mathrm{~km}^{2}$ (Figure 7d). On the contrary, some of our conclusions were different from others. For example, Ramankutty and Foley $(1998,1999)$ determined that the global cultivated land area was $1800 \times 10^{4} \mathrm{~km}^{2}$ in the early $1990 \mathrm{~s}$ and that the lands were mainly located in Eurasia, followed by North America and Africa. However, our study showed that the global cultivated land area was $1845.761 \times 10^{4} \mathrm{~km}^{2}$ in the early $1990 \mathrm{~s}$, and that the lands were primarily located in southern Europe, northeastern Mongolia, eastern China, the Great Lakes area and the Mississippi River basin in the United States, sub-Saharan Africa, southern Congo and the southern Democratic Republic of the Congo. In addition, because the study period in this paper included the most recent 30 years, the study period and some of our conclusions were different from other research.

(2) Due to the large spatial scale covered in our study, the spatial resolution was not very high. Therefore, we focused on the areas with a high percentage of cultivated land change and the concentrated areas that had cultivated land change. The dispersed or relatively small areas with cultivated land change were not described in detail. Due to the length limit of this paper, we only analyzed this change in different continents, and we did not examine the cultivated land distribution and the spatial pattern of cultivated land change in each country. In addition, there was a significant amount of work involved in converting, cropping and overlaying the image layers used in our data analysis. Consequently, this may have resulted in some errors that could have affected the accuracy of our results.

(3) As can be seen by comparing Figure 3 and 8, the expansion of cultivated lands to high latitudes exhibited in all the continents analyzed, to different extents, indicates that global warming has provided a natural condition for this type of expansion. On the other hand, 
global warming also promotes the expansion of cultivated lands to high altitude areas. Accordingly, next we will investigate the influence of global warming on cultivated land expansion using global elevation data.

Table 6 Comparisons between our results and the results of previous studies

\begin{tabular}{l} 
The results of previous studies \\
\hline 1 Xie and Cheng (1999) reported that the global \\
cultivated lands showed an increasing trend be- \\
fore 1985 and a decreasing trend between 1985 \\
and 1995. \\
Lepers et al. (2005) found that the global culti- \\
vated land increased from 1981 to 1990 in all the \\
continents analyzed, and that the main areas that \\
increased were in southeastern Asia, Bangladesh, \\
the Indus River basin, Middle East, Central Asia \\
and the Great Plains of the United States.
\end{tabular}

3 Waisanen and Bliss (2002) demonstrated that the cultivated land area in the United States showed an increasing trend from 1982 to 1992.

Du et al. (2015) indicated that from 1980 to 2005 the cultivated lands of Brazil increased rapidly in all regions except the northern tropical rain forest area.

5 Dewan and Yamaguchi (2009) reported that from 1960 to 2005 the cultivated lands in Bangladesh continuously declined and that it was due to conversion into woodlands and construction lands.

Abbas (2009) determined that from 1975 to 2005 the cultivated land in Nigeria expanded towards the southern forest area, while the original cultivated land area reduced.

$7 \quad$ Müller and Sikor (2006) found that many cultivated lands were abandoned in southeastern Albania from 1988 to 2003 .

8 Ramankutty and Foley (1998) reported that the global cultivated land area was $1800 \times 10^{4} \mathrm{~km}^{2}$; the land was concentrated in Asia and Europe, followed by North America and Africa in the 1990s.

Ramankutty and Foley (1999) determined that the cultivated land area showed an increasing trend from 1700 to 1992. After 1700, the fastest expansion of cultivated lands occurred in Europe, followed by North America and South America.

10 Goldewijk et al. (2011) examined the data of global cultivated lands from 1700 to 1990, and concluded that the global cultivated land area increased by 5.5 -fold during the past three centuries.
Our results

We found that the global cultivated lands showed a decreasing trend between 1985 and 1995. We further pointed out that the reduction was not significant at a rate of $19.772 \times 10^{4} \mathrm{~km}^{2} / \mathrm{a}$.

The cultivated lands had an increasing trend in Asia and South America from 1982 to 1990, but the cultivated lands had a decreasing trend in other continents. The areas with increased cultivated lands were mainly located in southeastern Asia and sub-Saharan Africa, and the areas with reduced cultivated lands were primarily distributed in the areas near the equator in Africa, southeastern United States and eastern China (Figure 6).

We found that the cultivated lands in the United States increased from 1982 to 1992, but the increase was not significant. The increased areas were mainly located in central and western regions (Figure 7a).

The cultivated lands of Brazil presented an increasing trend from 1980 to 2005 , this was mainly due to converted grasslands and woodlands (Figure $7 b)$.

Between 1982 and 2005 the cultivated lands in Bangladesh showed a rapid decrease that was mainly due to conversion into grasslands and woodlands (Figure 7c).

The cultivated lands in Nigeria expanded by $214197.544 \mathrm{~km}^{2}$ towards the southern forest area, while the original cultivated lands reduced by $187354.798 \mathrm{~km}^{2}$ from 1982 to 2005 (Figure 7d).

The cultivated land area in Albania significantly reduced from 1988 to 2003; the decrease was mainly due to a conversion into grasslands.

We calculated the global cultivated land area as $1845.761 \times 10^{4} \mathrm{~km}^{2}$. The lands were mainly located in southern Europe, northeastern Mongolia, eastern China, the area near the Great Lakes and Mississippi River basin in the United States, sub-Saharan Africa, Republic of the Congo, and southern Democratic Republic of the Congo in Africa.

We analyzed the spatial change of global cultivated lands from 1982 to 2011, which was very recent and covered a short time span. Moreover, we found that the most rapid cultivated land expansion occurred in Oceania.

We analyzed the spatial change of global cultivated lands from 1982 to 2011, and concluded that the global cultivated land area increased by 1.273 -fold during the past 30 years. 


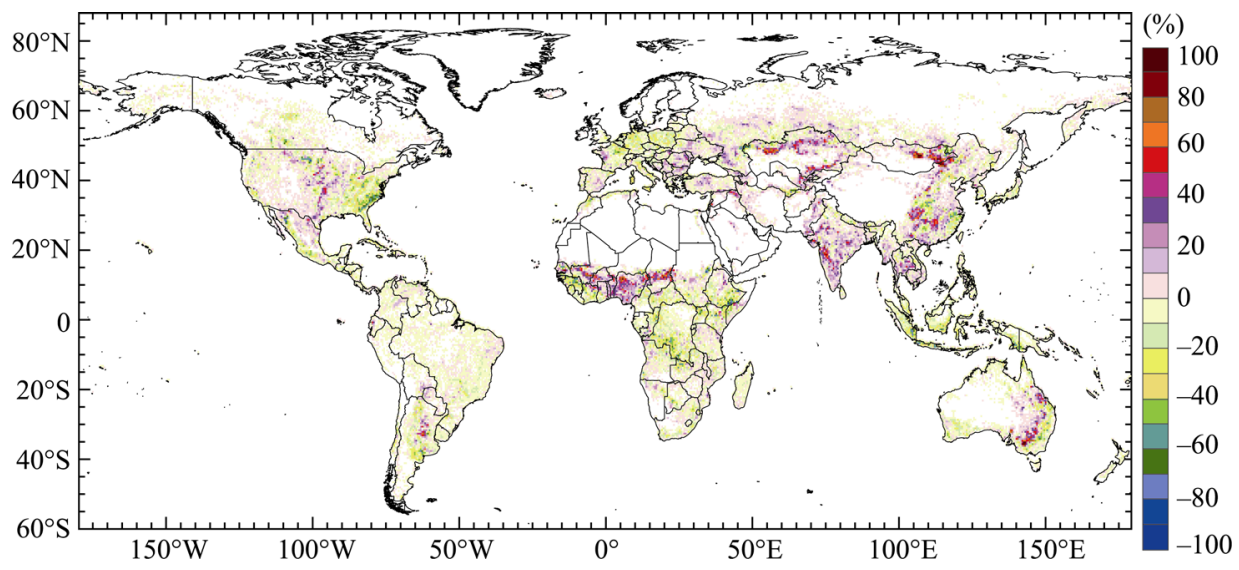

Figure 6 The spatial change of global cultivated lands from 1982 to 1990

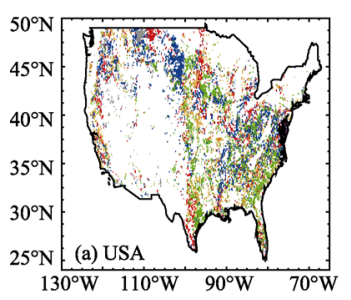

Woodland to cropland
Grassland to cropland
Built-up land to cropland

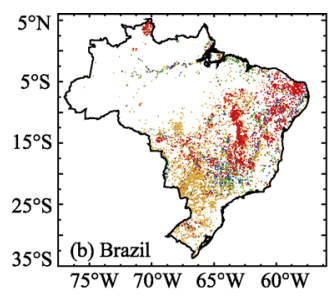

Wetland to cropland
Water body to cropland
Unused land to cropland

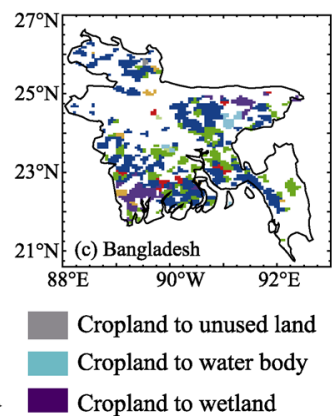

Cropland to wetland

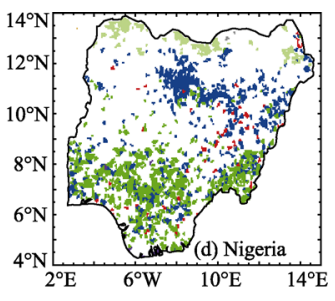

Cropland to built-up land Cropland to grassland

Cropland to woodland

Figure 7 The spatial distribution of cultivated land conversions in different countries

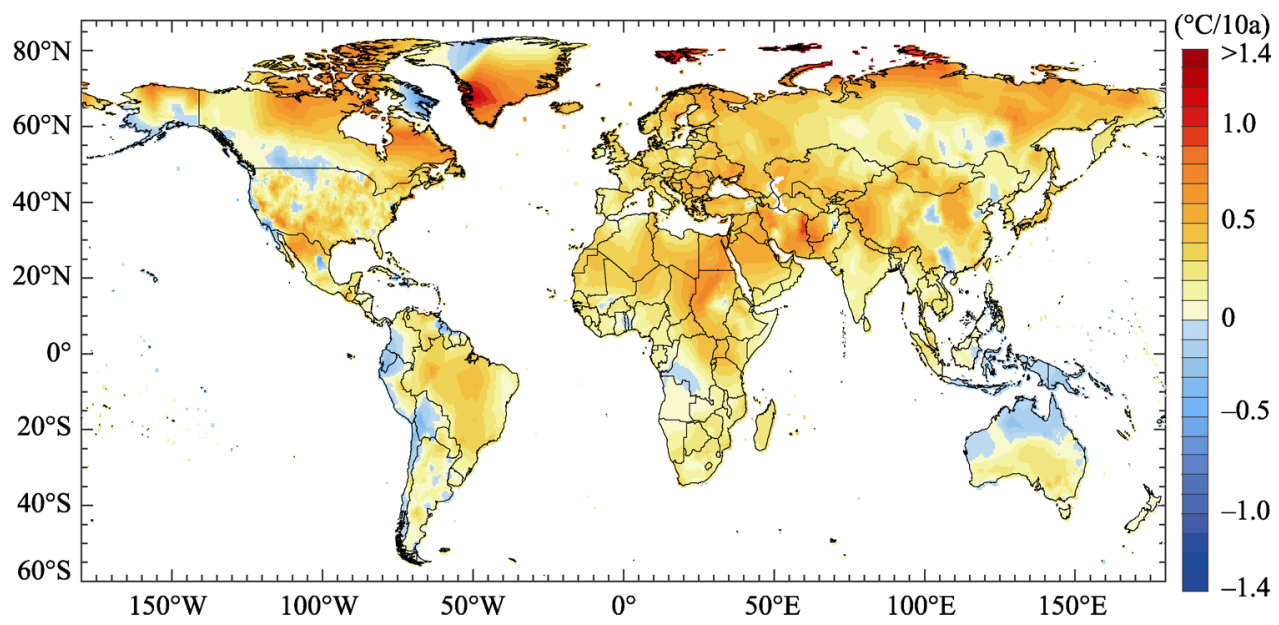

Figure 8 The spatial distribution of global temperature change since the 1980s

\section{Conclusions}

(1) From 1982 to 2011, the global cultivated land area increased at a rate of $7.920 \times 10^{4} \mathrm{~km}^{2} / \mathrm{a}$, although this increase was not significant. The total cultivated land increase over time was $528.768 \times 10^{4} \mathrm{~km}^{2}$. The global cultivated land area increased in the $1980 \mathrm{~s}$ and $2000 \mathrm{~s}$ and de- 
creased in the 1990s. The increased cultivated lands were mainly converted from grasslands, woodlands and unused lands, which were also the three types of land to which cultivated lands were mainly converted.

(2) Since the $1980 \mathrm{~s}$, cultivated land areas increased by $170.854 \times 10^{4} \mathrm{~km}^{2}, 107.890 \times 10^{4} \mathrm{~km}^{2}$, and $186.492 \times 10^{4} \mathrm{~km}^{2}$ in North America, South America, and Oceania, respectively, while respective decreases in cultivated land areas of $23.769 \times 10^{4} \mathrm{~km}^{2}, 4.035 \times 10^{4} \mathrm{~km}^{2}$, and $86.76 \times 10^{4} \mathrm{~km}^{2}$ occurred in Asia, Europe and Africa. The cultivated land areas increased significantly in North America and South America and decreased significantly in Asia. The cultivated land in North America showed the fastest increase in the most recent 10 years and South America showed the fastest increase in cultivated land in the 1980s. The cultivated land in Asia continued to decline after the 1990s. The newly increased cultivated lands were primarily converted from grasslands, woodlands and unused lands in each continent analyzed, and the decreased cultivated lands were converted to grasslands and woodlands.

(3) The global increase in cultivated lands was concentrated in southern and central Africa, eastern and northern Australia, southeastern South America, central United States and Alaska, central Canada, western Russia, northern Finland and northern Mongolia. The highest increase was found in Botswana in southern Africa, which showed an $80 \%-90 \%$ increase. On the other hand, the decrease in cultivated lands was concentrated in southern Sudan in central Africa, mid-southern United States, southern Russia and countries in southern Europe, including Bulgaria, Romania, Serbia, and Hungary. The highest decrease was found in southern Africa, southeastern United States, and southwestern Russia.

(4) The cultivated lands in all continents analyzed showed a trend towards expanding to high latitudes. Meanwhile, the spatial pattern of cultivated lands exhibited the characteristics of the expansion of newly increased cultivated lands and the reduction of original cultivated lands observed in most countries.

\section{References}

Abbas I I, 2009. An overview of land cover changes in Nigeria, 1975-2005. Journal of Geography \& Regional Planning, 5(12): 62-65.

Chhabra A, Geist H, Houghton R A et al., 2006. Multiple impacts of land-use/cover change. In: Land-Use and Land-Cover Change. Berlin and Heidelberg: Springer, 71-116.

Dewan A M, Yamaguchi Y, 2009. Using remote sensing and GIS to detect and monitor land use and land cover change in Dhaka Metropolitan of Bangladesh during 1960-2005. Environmental Monitoring \& Assessment, 150(150): 237-249.

Du Guoming, Kuang Wenhui, Meng Fanhao et al., 2015. Spatiotemporal pattern and driving forces of land use/cover change in Brazil. Progress in Geography, 34(1): 73-82. (in Chinese)

Findell K L, Pitman A J, England M H et al., 2009. Regional and global impacts of land cover change and sea surface temperature anomalies. Journal of Climate, 22(12): 3248-3269.

Forster P, Ramaswamy V, Artaxo P et al., 2007. Changes in atmospheric constituents and in radiative forcing. Climate Change 2007: The Physical Science Basis Contribution of Working Group I to the Fourth Assessment Report of The Intergovernmental Panel on Climate Change. Cambridge, UK: Cambridge University Press.

Godfray H C, Beddington J R, Crute L R et al., 2010. Food security: The challenge of feeding 9 billion people. Science, 327(5967): 812-818.

Goldewijk K K, Beusen A, Drecht G V et al., 2011. The HYDE 3.1 spatially explicit database of human-induced global land-use change over the past 12,000 years. Global Ecology and Biogeography, 20(1): 73-86.

He Fanneng, Li Meijiao, Liu Haolong, 2016. Reconstruction of cropland area at Lu scale and its spatial-temporal 
characteristics in the Northern Song Dynasty. Acta Geographica Sinica, 71(11): 1967-1978. (in Chinese)

Hudson W D, 1987. Correct formulation of the Kappa coefficient of agreement. Photogrammetric Engineering \& Remote Sensing, 53(4): 421-422.

Lepers E, Lambin E F, Janetos A C et al., 2005. A synthesis of information on rapid land-cover change for the period 1981-2000. BioScience, 55(2): 115-124.

Liu Jiyuan, 2000. A study on spatial-temporal feature of modem land use change in China. Quaternary Sciences, 20(3): 229-239. (in Chinese)

Liu Jiyuan, Kuang Wenhui, Zhang Zengxiang et al., 2014. Spatiotemporal characteristics, patterns and causes of land use changes in China since the late 1980s. Acta Geographica Sinica, 69(1): 3-14. (in Chinese)

Liu Yang, Liu Ronggao, 2015. Retrieval of global long-term leaf area index from LTDR AVHRR and MODIS observations. Journal of Geo-Information Science, 17(11): 1304-1312. (in Chinese)

Ma Kaiyu, Ding yuguo,Tu Qipu et al., 1993. Principles and Methods of Climate Statistics. Beijing: China Meteorological Press, 77-82. (in Chinese)

Müller D, Sikor T, 2006. Effects of postsocialist reforms on land cover and land use in south-eastern Albania. Applied Geography, 26(3): 175-191.

Ramankutty N, Achard F, Alves D et al., 2005. Global changes in land cover. IHDP Newsletter, (3): 4-5.

Ramankutty N, Delire C, Snyder P, 2006. Feedbacks between agriculture and climate: An illustration of the potential unintended consequences of human land use activities. Global and Planetary Change, 54(1/2): 79-93.

Ramankutty N, Evan A T, Monfreda C et al., 2008. Farming the planet: 1. Geographic distribution of global agricultural lands in the year 2000. Global Biogeochemical Cycles, 22(1): 567-568.

Ramankutty N, Foley J A, 1998. Characterizing patterns of global land use: An analysis of global croplands data. Global Biogeochemical Cycles, 12(4): 667-685.

Ramankutty N, Foley J A, 1999. Estimating historical changes in global land cover: Croplands from 1700 to 1992. Global Biogeochemical Cycles, 13(4): 997-1027.

Shang Rong, Liu Ronggao, Liu Yang, 2015. Generation of global long-term albedo product based on the background knowledge. Journal of Geo-Information Science, 17(11): 1313-1322. (in Chinese)

Shi Peijun, Wang Jing'ai, Chen Jing et al., 2006. The future of human-environment interaction research in geography: Lessons from the 6th Open Meeting of IHDP. Acta Geographica Sinica, 61(2): 115-126. (in Chinese)

Shi Xueli, Zhang Fang, Zhou Wenyan et al., 2015. Impacts of CG-LTDR land cover dataset updates on the ground temperature simulation with BCC_AVIM 1.0. Journal of Geo-Information Science, 17(11): 1294-1303. (in Chinese)

Tao B, Tian H Q, Chen G S et al., 2013. Terrestrial carbon balance in tropical Asia: Contribution from cropland expansion and land management. Global and Planetary Change, 100(1): 85-98.

Tian H Q, Chen G S, Zhang Chi et al., 2012. Century-scale responses of ecosystem carbon storage and flux to multiple environmental changes in the southern United States. Ecosystems, 15(4): 674-694.

Waisanen P J, Bliss N B, 2002. Changes in population and agricultural land in conterminous United States counties, 1790 to 1997. Global Biogeochemical Cycles, 16(4): 84-1-84-19.

Xie Gaodi, Cheng Shengkui, 1999. A study on global land use change under the pressure of population growth. Journal of Natural Resources, 14(3): 193-199. (in Chinese)

Ye Yu, Fang Xiuqi, Ren Yuyu et al., 2009. Coverage changes of cropland in northeast China during the past 300 years. Science in China Series D: Earth Sciences, 39(3): 340-350. (in Chinese)

Zhao Wenwu, 2012. Arable land change dynamics and their driving forces for the major countries of the world. Acta Ecologica Sinica, 32(20): 6452-6462. (in Chinese) 